\title{
PERSPECTIVE
}

\section{An Entrustable Professional Activity (EPA)-Based Framework to Prepare Fourth-Year Medical Students for Internal Medicine Careers}

D. Michael Elnicki, MD ${ }^{1,2}$, Meenakshy K. Aiyer, MD ${ }^{3}$, Maria L. Cannarozzi, MD4, Alexander Carbo, $M D^{5}$, Paul R. Chelminski, $M D^{6}$, Shobhina G. Chheda, $M D^{7}$, Saumil M. Chudgar, MD ${ }^{8}$, Heather E. Harrell, MD, L. Chad Hood, MD', Michelle Horn, MD ${ }^{10}$, Karnjit Johl, MD ${ }^{11}$, Gregory C. Kane, MD ${ }^{12}$, Diana B. McNeill, MD ${ }^{8}$, Marty D. Muntz, MD ${ }^{13}$, Anne G. Pereira, $M D^{14}$, Emily Stewart, $M D^{12}$, Heather Tarantino, $M D^{15}$, and T. Robert Vu, $M D^{16}$

'University of Pittsburgh School of Medicine, Pittsburgh, PA, USA; ${ }^{2}$ University of Pittsburgh, Pittsburgh, PA, USA; ${ }^{3}$ University of Illinois College of Medicine at Peoria, Peoria, IL, USA; ${ }^{4}$ University of Central Florida College of Medicine, Orlando, FL, USA; ${ }^{5}$ Harvard Medical School, Beth Israel Deaconess Medical Center, Boston, MA, USA; ${ }^{6}$ University of North Carolina School of Medicine, Chapel Hill, NC, USA; 7 University of Wisconsin School of Medicine and Public Health, Madison, WI, USA; ${ }^{8}$ Duke University School of Medicine, Durham, NC, USA; ${ }^{9}$ University of Florida College of Medicine, Gainesville, FL, USA; ${ }^{10}$ University of Mississippi School of Medicine, Jackson, MS, USA; " University of California-Davis School of Medicine, Sacramento, CA, USA; ${ }^{12}$ Sidney Kimmel Medical College at Thomas Jefferson University, Philadelphia, PA, USA; ${ }^{13}$ Medical College of Wisconsin, Milwaukee, WI, USA; ${ }^{14}$ University of Minnesota Medical School, Minneapolis, MN, USA; ${ }^{15}$ Carolinas Medical Center, Charlotte, NC, USA; ${ }^{16}$ Indiana University School of Medicine, Charlotte, NC, USA.

The purpose of the fourth year of medical school remains controversial. Competing demands during this transitional phase cause confusion for students and educators. In 2014, the Association of American Medical Colleges (AAMC) released 13 Core Entrustable Professional Activities for Entering Residency (CEPAERs). A committee comprising members of the Clerkship Directors in Internal Medicine and the Association of Program Directors in Internal Medicine applied these principles to preparing students for internal medicine residencies. The authors propose a curricular framework based on five CEPAERs that were felt to be most relevant to residency preparation, informed by prior stakeholder surveys. The critical areas outlined include entering orders, forming and answering clinical questions, conducting patient care handovers, collaborating interprofessionally, and recognizing patients requiring urgent care and initiating that care. For each CEPAER, the authors offer suggestions about instruction and assessment of competency. The fourth year of medical school can be rewarding for students, while adequately preparing them to begin residency, by addressing important elements defined in the core entrustable activities. Thus prepared, new residents can function safely and competently in supervised postgraduate settings.

KEY WORDS: medical education; medical education-assessment; medical education-mentoring; medical education-undergraduate; medical education curriculum development/assessment; clinical skills assessment

J Gen Intern Med 32(11): 1255-60

DOI: $10.1007 / \mathrm{s} 11606-017-4089-8$

(c) Society of General Internal Medicine 2017

Received December 7, 2016

Revised April 12, 2017

Accepted May 19, 2017

Published online June 20, 2017
Traditionally, the fourth year of medical school has been a 1 less structured interlude between the first three years of medical school and residency, which has afforded medical students greater flexibility for academic and career planning. The lack of standardized curricula and assessments, along with the competing demands of residency application, has raised concerns about the educational value of the fourth year. Amid this debate, some have questioned the need for the fourth year, citing educational debt and physician shortages. ${ }^{1,2}$ Examples exist of medical schools with three-year curricula, but they are usually small projects focusing on primary care or care for the underserved. ${ }^{3-5}$ Medical educators are increasingly concerned that the fourth year is neither optimally preparing medical students for their future careers nor meeting patient and societal needs. A sharper focus on educational purpose and outcomes is needed. ${ }^{6,7}$

Entrustable Professional Activities (EPAs) were initially proposed for graduate medical education, but have gained support for adoption in undergraduate medical education. ${ }^{8}$ In 2014, the Association of American Medical Colleges (AAMC) responded to concerns from residency program directors about the inadequate preparation of medical students for internship and residency. They advanced 13 EPAs considered essential for entering residency, the Core Entrustable Professional Activities for Entering Residency (CEPAERs). ${ }^{9}$ These are responsibilities that learners are entrusted with performing without direct supervision after they have achieved sufficient milestones across various competencies. ${ }^{10}$

This paper presents the final recommendations of the Alliance for Academic Internal Medicine (AAIM) Medical Student to Resident Interface Committee. The committee comprised members from two of AAIM's constituent bodies (Clerkship Directors in Internal Medicine and Association of 
Program Directors in Internal Medicine). The committee met in person and via a series of telephone conferences until it reached consensus on both structure and content of the recommendations. Final writing tasks were performed by subcommittees and then reviewed by the entire group. The AAIM board of directors subsequently reviewed and endorsed these recommendations as a policy statement.

The purpose of this paper is to propose a curricular framework that will prepare fourth-year medical students for internal medicine training. Informed by survey data from internal medicine program directors, clerkship directors, and residents, ${ }^{11-14}$ our proposal is organized around five CEPAERs that these groups found particularly relevant to preparation for residency (Table 1). We chose this approach because EPAs apply a common framework to the recommendations, ${ }^{15}$ whereas the skills emphasized in specific courses vary among institutions.

The clerkship year of medical school transitions students from the classroom to clinical immersion as the primary learning environment. Students need to develop proficiency in a number of core clinical skills during clerkships (Table 1). These skills generally cover the breadth of Pangaro's "reporter" stage of professional development, ${ }^{16}$ and include the ability to conduct an accurate history and physical examination, present relevant findings, and complete written documentation of encounters. Additionally, most students develop "interpreter" skills such as generating a differential diagnosis and interpreting diagnostic studies. The committee felt that acquisition of these skills equated to developing sufficient competence in several CEPAERs - specifically 1, 2, 3, 5, 6, and 11 - prior to the fourth year, and these are not addressed here. In addition, although students develop procedural and systems skills during the fourth year, CEPAERs 12 and 13 require longitudinal learning that spans undergraduate and graduate medical education, and we did not include them here.

Five CEPAERs are most appropriate developmentally for the fourth year, or post-clerkship phase, of medical school curricula (Table 1), and it is on these five that we focused. For each CEPAER, we chose to explain its importance and suggest where the EPA could be taught and evaluated (Table 2).
- EPA 4: Enter orders/prescriptions

- EPA 7: Form clinical questions and retrieve evidence to advance patient care

- EPA 8: Give or receive a patient handover to transition care responsibility

- EPA 9: Collaborate as a member of an interprofessional team

- EPA 10: Recognize a patient requiring urgent or emergency care, initiate evaluation and management

The selection of these EPAs was informed by the expressed priorities of stakeholders. A 2013 survey asked internal medicine residents to identify the most important skills to be learned prior to internship. Identifying when to seek additional expertise, prioritizing clinical tasks, managing time efficiently, and communicating with other providers around care transitions were rated the highest. ${ }^{13}$ In 2010, program directors in internal medicine prioritized knowing when to seek assistance, communicating with patients and nurses, recognizing seriously ill patients, and time management as essential skills for interns. ${ }^{11}$ In a 2013 national survey of clerkship directors in internal medicine, the most highly rated recommendation for acquiring the needed skills to perform well as an intern was for a sub-internship in internal medicine. ${ }^{12}$

The debate on the fourth year of medical school must acknowledge the multiple roles that this year plays in students' career development. Much of the fourth year is spent on the residency matching process, primarily in preparing applications and navigating the interview process. Many students also feel the need to devote time to audition rotations. While the value of these rotations in matching to a residency in internal medicine is unclear, evidence from other specialties supports this practice. ${ }^{17,18}$ Significant variability in assessment processes among schools makes it difficult to ensure appropriate evaluation of students in audition rotations. The CEPAERs provide a limited list of activities that form a common language for assessment across institutions. As medicine increasingly embraces the concept of competency-based education, it is important to consider students who required more time than peers. Students need sufficient time to prepare for and to complete the United States Medical Licensing Examination

Table 1 EPAs and Medical School Year for Developing Proficiency

\begin{tabular}{|c|c|c|c|}
\hline & Pre-clerkship & Clerkship/M3 & Post-clerkship/M4 \\
\hline 1. Gather a history and perform a physical examination & $\mathrm{X}$ & $\mathrm{X}$ & \\
\hline 2. Prioritize differential diagnosis following a clinical encounter & & $\mathrm{X}$ & \\
\hline 3. Recommend and interpret common diagnostic and screening tests & & $\mathrm{X}$ & \\
\hline 4. Enter and discuss orders and prescriptions & & & $\mathrm{X}$ \\
\hline 5. Document a clinical encounter in the patient record & & $\mathrm{X}$ & \\
\hline 6. Provide an oral presentation of a clinical encounter & $\mathrm{X}$ & $\mathrm{X}$ & \\
\hline 7. Form clinical questions and retrieve evidence to advance patient care & & & $\mathrm{X}$ \\
\hline 8. Give or receive a patient handover to transition care responsibility & & & $\mathrm{X}$ \\
\hline 9. Collaborate as a member of an interprofessional team & & $\mathrm{X}$ & $\mathrm{X}$ \\
\hline $\begin{array}{l}\text { 10. Recognize a patient requiring urgent or emergency care and initiate evaluation } \\
\text { and management }\end{array}$ & & & $\mathrm{X}$ \\
\hline 11. Obtained informed consent for tests and/or procedures & & $\mathrm{X}$ & \\
\hline 12. Perform general physician procedures & & $\mathrm{X}$ & $\mathrm{X}$ \\
\hline 13. Identify system failures and contribute to a culture of safety and improvement & $\mathrm{X}$ & $\mathrm{X}$ & $\mathrm{X}$ \\
\hline
\end{tabular}


Table 2 The Most Appropriate EPAs for the Final Phase of Medical School and Where They Can Be Achieved

\begin{tabular}{|c|c|c|c|c|c|c|}
\hline & $\begin{array}{l}\text { IM Sub- } \\
\text { internship }\end{array}$ & $\begin{array}{l}\text { ICU or } \\
\text { EM }\end{array}$ & $\begin{array}{l}\text { Clinical } \\
\text { electives* }\end{array}$ & $\begin{array}{l}\text { Research } \\
\text { electives }^{\dagger}\end{array}$ & Simulation $^{*}$ & Capstones $^{\S}$ \\
\hline EPA 4: Enter and discuss orders & $\mathrm{X}$ & $\mathrm{X}$ & & & $\mathrm{X}$ & $\mathrm{X}$ \\
\hline $\begin{array}{l}\text { EPA: 7: Form clinical questions and retrieve } \\
\text { evidence }\end{array}$ & $\mathrm{X}$ & $\mathrm{X}$ & $\mathrm{X}$ & $X$ & $\mathrm{X}$ & $\mathrm{X}$ \\
\hline EPA 8: Give or receive patient handovers & $\mathrm{X}$ & $\mathrm{X}$ & & & $\mathrm{X}$ & $X$ \\
\hline EPA 9: Collaborate in healthcare teams & $\mathrm{X}$ & $\mathrm{X}$ & $\mathrm{X}$ & $\mathrm{X}$ & & \\
\hline $\begin{array}{l}\text { EPA 10: Recognize patients requiring urgent/ } \\
\text { emergency care }\end{array}$ & $\mathrm{X}$ & $\mathrm{X}$ & & & $\mathrm{X}$ & $\mathrm{X}$ \\
\hline
\end{tabular}

IM internal medicine, ICU intensive care unit, EM emergency medicine

*Clinical electives: (e.g. consultative services)

${ }^{\prime}$ Research electives: (e.g. involvement in ongoing or self-designed research projects)

Simulation: clinical scenarios using either standardized patients or mannequins

${ }^{\S}$ Capstones: or intern boot camps, courses summarizing important concepts of medical school and prepping students for internship

(USMLE) Step 2 requirements for graduation and licensure.

Given the significant variability in curricular structure, content, and assessment of learners during the fourth year, a shift to what is expected on day 1 of internship offers a better perspective on how medical students should be trained and evaluated. Recent surveys of internal medicine program directors on their expectations of the entering intern with respect to the CEPAERs noted that over $90 \%$ of program directors expected their interns to be entrusted with the responsibility for gathering an accurate history, performing a detailed physical exam, delivering an oral presentation of relevant information, and providing organized, accurate documentation of the clinical encounter. Program directors also expect July interns to be able to participate as contributing clinicians, recognize patients requiring urgent or emergency care, initiate evaluation and management, enter patient orders, and give or receive a patient handover to transition care responsibility. ${ }^{11,14}$

\section{EPA 4: ENTER ORDERS/PRESCRIPTIONS}

Medication errors account for thousands of lives lost yearly and severely impact the healthcare system. ${ }^{19}$ Appropriate and accurate entry of orders is a skill that all interns need at the start of residency, as they are responsible for the majority of patient orders and will care for complicated patients.

In the post-clerkship phase, students should be expected to enter orders with supervision and feedback from residents or faculty members during clinical rotations. During the internal medicine sub-internship, students write both admission and discharge orders and enter management plans throughout their patients' hospitalizations. Workplace assessment and formative feedback on students' order entry can be provided by the residents and attending physicians. Capstone courses and objective structured clinical exams (OSCEs) offer venues for direct observation and feedback on students' order-writing skills, but occur in less realistic settings.

The limited literature on appropriate assessment methods for observing and evaluating order entry and prescription writing favors OSCEs over the use of standardized checklists for performing workplace assessments. A structured review of OSCE literature concluded that OSCEs were a feasible method for assessing competence in "management-prescription writing. $" 20$

\section{EPA 7: FORM CLINICAL QUESTIONS AND RETRIEVE EVIDENCE TO ADVANCE PATIENT CARE}

The Accreditation Council for Graduate Medical Education (ACGME) program requirements for internal medicine state that residents "must demonstrate the ability to evaluate their care of patients, appraise and assimilate scientific evidence, and continuously improve patient care based on constant selfevaluation and life-long learning." ${ }^{21}$ Students need to develop the ability to justify clinical decisions based on current evidence. Internists expect that patient care will be evidencebased, and interns will regularly be asked to support their decision making process with citations from the medical literature.

Clinical rotations involving direct patient care are best suited for teaching and assessing this EPA. These include the internal medicine sub-internship and subspecialty consultation rotations or rotations in ambulatory or intensive care unit (ICU) or emergency medicine (EM) settings. Additionally, a capstone course or research elective can reinforce foundational concepts of evidence-based medicine (EBM) such as biostatistics, clinical epidemiology, and clinical decision-making. ${ }^{22}$ Teaching methods may include journal clubs or EBM assignments where students are expected to demonstrate the steps of the EBM process.

Validated instruments for assessing EBM competence include the Berlin Questionnaire ${ }^{23}$ and the Fresno Test. ${ }^{24}$ The former instrument evaluates skills such as developing clinical questions or search strategies. The Fresno Test requires written short-answer demonstration of knowledge and skills across the first four steps of the EBM process applied to clinical scenarios. A computer-based OSCE station for evaluating competence in EBM skills for fourth-year medical students has been developed and validated..$^{25}$ Despite validated assessment tools, however, the teaching and evaluation of EBM skills requires faculty development to ensure that evaluators have sufficient EBM skills. 


\section{EPA 8: GIVE OR RECEIVE PATIENT HANDOVER TO TRANSITION CARE RESPONSIBILITY}

Transitions of patient care between providers are high-risk periods, posing patient safety concerns. Internal medicine residents transition patient care regularly, and interns will be expected to provide patient handoffs in standardized verbal and written formats to other healthcare providers. The knowledge, skills, and attitudes leading to effective handoffs include succinctness, prioritization of patient information, and action and contingency planning. ${ }^{26}$ Students should recognize the attributes of an effective handoff, including effective communication techniques.

The internal medicine sub-internship provides multiple opportunities for students to provide handoffs to the on-call team and the primary care physician at discharge. ICU and EM rotations provide opportunities to perform handovers of critically ill patients across clinical settings. Standardization of handover techniques (using mnemonics or checklists) helps ensure the safe and efficient transition of critically ill patients in stressful situations. ${ }^{27,28}$ Capstone courses may provide an additional opportunity to practice handoff skills and receive feedback. ${ }^{29}$

Generally, reliable assessment by direct observation requires multiple observations and extensive faculty development. ${ }^{30}$ Aylard and colleagues described a framework using the handoff EPA model to engage stakeholders and developed assessment tools to provide formative feedback and summative entrustment decision for interns. ${ }^{31}$ OSCEs can be used during sub-internships or the intern boot camp to assess handoff skills. ${ }^{32}$ OSCEs specific to the process of patient care transitions have recently been developed and validated. ${ }^{33,34}$

\section{EPA 9: COLLABORATE AS A MEMBER OF AN INTERPROFESSIONAL TEAM}

In 2013, the National Academy of Medicine released a report challenging medical educators to teach trainees to care for patients in interprofessional models. ${ }^{35}$ Over $90 \%$ of internal medicine program directors feel that beginning interns should be able to participate on an interprofessional team. ${ }^{11}$

Students in clinical settings will need to collaborate with nurses, social workers, pharmacists, physical therapists, physician assistants, and others. Potential interprofessional curriculum elements include standardized clinical scenarios that allow learners to assume roles of other professionals on their team, structured interprofessional huddles before inpatient rounds or clinic, and rotating with members of an interprofessional team. Some medical schools have developed interprofessional clinics where students and faculty members from various professional schools care for patients together. ${ }^{36,37}$

This EPA is ideally suited for 360-degree evaluations, and peer-driven feedback given by team members would be particularly useful. A validated tool, the Teamwork Mini-Clinical Evaluation Exercise (TMEX), is available for assessing interprofessional communication. ${ }^{38}$

\section{EPA 10: RECOGNIZE A PATIENT REQUIRING URGENT OR EMERGENCY CARE AND INITIATE EVALUATION AND MANAGEMENT}

The concept of recognizing a patient who is "sick versus not sick" is a message continually emphasized during internal medicine residency training. Virtually all (96\%) internal medicine program directors surveyed selected "knowing when to seek assistance" as a high-priority skill for incoming interns. ${ }^{11}$

A sub-internship in internal medicine, ICU, or EM rotation and other clinical rotations requiring transitions between parts of the health system will expose students to patients requiring urgent care. Management of critically ill patients is further emphasized in an ICU rotation, though direct student involvement with these complex patients may be limited. The recognition and management of severe illness is well defined (e.g. hypoxia, hypotension, or delirium) and can serve as the core for a standardized curriculum on recognizing seriously ill patients.

Assessing student skills in this area may be performed in several different settings. While direct observation with feedback by residents or attending physicians may be the most accurate, its practice may be erratic. Some schools use simulation, where students attempt to manage urgent concerns or critically ill patients. Other options include simulated pages that are done as part of a sub-internship or capstone course. Students are paged by a "nurse" with concerns about a patient to simulate patient management, after which they are given feedback on their performance, including ideas for further evaluation and management. Sample scenarios for simulated pages are available and can serve as a method for assessing competence in this area. ${ }^{39}$

\section{CONCLUSIONS}

The fourth year of medical school must be balanced to provide students with the skills necessary to succeed as first-year internal medicine residents while also addressing competing needs. We feel that the focus should be on learning outcomes that allow each medical school to offer its own curriculum with its intrinsic strengths. We have delineated learning outcomes as CEPAERs, which medical educators agree are critical to students' future development as physicians. Other disciplines are also beginning to define their learning outcomes as CEPAERs. Carrachio et al. recently described an EPA-based pathway for assessing the continuum of the educational process in pediatrics. ${ }^{40}$ A group of family physicians has proposed a set of EPAs to guide family medicine residencies. ${ }^{41}$ The pilot schools commissioned by the AAMC to implement the core EPA framework recently highlighted guiding principles to consider when using this framework for undergraduate medical education ${ }^{42}$.

The final phase of medical school should address key elements such that the core entrustable activities for entering residency are met. We are not suggesting that the academic year should be either lengthened or shortened, but simply that it 
address these important elements. We have focused on what we consider most appropriate for students entering internal medicine training, in order to lead seamlessly toward the EPAs expected of internal medicine residents. ${ }^{43}$ Our focus was on guiding the initial development of future internists who will step confidently into supervised postgraduate training, ${ }^{44}$ so that they can function safely and competently, ultimately acquiring the skills necessary for independent and satisfying practice.

\section{Acknowledgments:}

The authors would like to acknowledge the support of the Alliance for Academic Internal Medicine staff, especially Chris Williams, in support of the Medical Student to Resident Interface Committee and Ana Lucia Arita for assistance with manuscript preparation.

Contributors: The Alliance for Academic Internal Medicine (AAIM) board of directors and the Society for General Internal Medicine (SGIM) council reviewed and approved the manuscript.

Corresponding Author: D. Michael Elnicki, MD; Office of Medical Education University of Pittsburgh, Pittsburgh, PA, USA (e-mail:dme101@pitt.edu).

\section{Compliance with Ethical Standards:}

Disclaimer: The perspectives and findings discussed in this manuscript do not necessarily reflect the views of the AAMC or the Core EPAs for Entering Residency Pilot Program.

Conflict of Interest: The authors declare that they do not have a conflict of interest.

\section{REFERENCES}

1. Abramson SB, Jacon D, Rosenfeld M, et al. A 3-year M. D.- accelerating careers, diminishing debt. N Engl J Med 2013;369(12):1085-1089.

2. Emanuel E, Fuchs VR. Shortening medical training by $30 \%$. JAMA Intern Med. 2012;307(11):1143-1144.

3. Raymond JR, Kerschner JE, Hueston WJ, Maurana CA. The merits and challenges of three-year medical school curricula: time for an evidence-based discussion. Acad Med. 2015;90(10): 1-6

4. Cangiarella J, Fancher T, Jones B, et al. Three-year MD programs: perspectives from the Consortium of Accelerated Medical Pathway Programs (CAMPP). Acad Med. 2017;92(4):483-90.

5. Green MM, Welty L, Thomas JX, Curry RH. Academic performance of students in an accelerated baccalaureate/MD program: implications for alternative physician education pathways. Acad Med 2016;91:256-261.

6. Lucey CR. Medical education: part of the problem and part of the solution. JAMA Intern Med 2013;173(17):1639-1643.

7. Fazio SB, Steinman AF. A new era for residency training in internal medicine. JAMA Intern Med 2016;176(2):161-162.

8. Chen HC, van der Broek WS, ten Cate $\mathbf{O}$. The case for entrustable professional activities in undergraduate medical education. Acad Med. 2015;90(4): 431-6

9. www.mededportal.org/icollaborative/resource/887. May 28, 2014. Accessed May 16, 2017.

10. ten Cate O. Nuts and bolts of entrustable professional activities. J Grad Med Educ. 2013; 5(1): 157-158.

11. Angus S, Vu R, Halvorsen AJ, et al. What skills should new internal medicine interns have in July? A national survey of internal medicine residency program directors. Acad Med. 2014;89:432-435.

12. Chretien KC, Elnicki, DM, Levine D, Aiyer M, Steinmann A, Willett LR. What are we telling our students? A national survey of clerkship directors' advice for students applying to internal medicine residency. J Grad Med Educ. 2015;7(3):382-387.

13. Pereira AG, Harrell HE, Weissman A, Smith CD, Dupras D, Kane GC. Important skills for internship and the fourth-year medical school courses to acquire them: a national survey of internal medicine residents. Acad Med. 2016;91:821-826.
14. Angus SV, Vu TR, Willett LL, Call S, Halvorsen AJ, Chaudhry S. Internal medicine residency program directors' views of the core entrustable professional activities for entering residency: an opportunity to enhance communication of competency along the continuum. Acad Med. 2017; 92(6):785-91. doi:10.1097/ACM.0000000000001419.

15. Englander R, Cameron T, Ballard AJ, Dodge J, Bull J, Aschenbrenner CA. Toward a common taxonomy of competency domains for the health professions and competencies for physicians. Acad Med 2013;88:1088-94.

16. Pangaro L. A new vocabulary and other innovations for improving descriptive in-training evaluations. Acad Med. 1999;74(11):1203-6.

17. Wood JS, David LR. Outcome analysis of factors impacting the plastic surgery match. Ann Plast Surg. 2010;64(6):770-774.

18. Baldwin $\mathbf{K}$, Weidner Z, Ahn J, Mehta S. Are away rotations critical for a successful match in orthopaedic surgery? Clin Orthop Relat Res. 2009;467:3340-3345

19. Nelson CE, Selbst SM. Electronic prescription writing errors in the pediatric emergency department. Pediatr Emerg Care. 2015;31(5):368 372.

20. Patricio MF, Juliao M, Fareleira F, Carneiro AV. Is the OSCE a feasible tool to assess competencies in undergraduate medical education? Med Teach. 2013;503-14.

21. ACGME Common program requirements for one year fellowships. http:// www.acgme.org/Portals/0/PFAssets/ProgramRequirements/one_year CPRs_categorization_070_12016.pdf). Accessed May 16, 2017.

22. Teo AR, Harleman E, O'Sullivan PS, Maa J. The key role of a transition course in preparing medical students for internship. Acad Med. 2011;86:860-865.

23. Fritsche L, Greenhalgh T, Falck-Ytter Y, Neumayer H-H, Kunz R. Do short courses in evidence based medicine improve knowledge and skills? Validation of Berlin questionnaire and before and after study of courses in evidence based medicine. BMJ. 2002;325:133841.

24. Ramos KD, Schafer S, Tracz SM. Validation of the Fresno Test of competence in evidence based medicine. BMJ. 2003;326:319-21.

25. Frohna JG, Gruppen LD, Fliegel JE, Mangrulkar RS. Development of an evaluation of medical student competence in evidence-based medicine using a computer-based OSCE station. Teach Learn Med. 2006;18(3):267-72.

26. Arora VM, Manjarrez E, Dressler DD, Basaviah P, Halasyamani L, Kripalani S. Hospitalist handoffs: a systematic review and task force recommendations. J Hosp Med 2009;4:422-40.

27. Harrell H, Aiyer M, Appel J, Dhaliwal G, Gliatto P, Sweet M. Primer to the internal medicine subinternship. MedPortal Publications; 2012;8:9277.

28. Reyes J, Greenberg L, Lesky L. ACCEPT medical student handoff workshop: the patient safety curriculum starts in undergraduate medical education. MedPortal Publications; 2015;11:10302.

29. Elnicki DM, Gallagher S, Willett L, et al. Course offerings in the fourth year of medical school: how U.S. medical schools are preparing students for internship. Acad Med. 2015;90(10):1324-1330.

30. Kogan JR, Holmboe E. Realizing the promise and importance of performance-based assessment. Teach Learn Med. 2013;25:568-574.

31. Aylward M, Nixon J, Gladding S. An entrustable professional activity (EPA) for handoffs as a model for EPA assessment development. Acad Med. 2014;89:1335-40.

32. Mischler M, Miller G, Aldag J, Aiyer MK. Last chance to observe: assessing residency preparedness following the 4th-year subinternship. Teaching Learn Med 2013;25(3):242.

33. Gaffney S, Farnan JM, Hirsch K, McGinty M, Arora VM. The modified, multi-patient observed simulated handoff experience (M-OSHE): assessment and feedback for entering residents on handoff performance. J Gen Intern Med. 2016;31(4):438-41.

34. Bloom-Fishbach K, Casey D, Schulson L, Gliatto P, Giftos J, Karani R. Health literacy in transitions of care: An innovative objective structured clinical examination for fourth-year medical students in an internship preparation course. J Gen Intern Med. 2015;31(2):242-6.

35. Institute of Medicine. Interprofessional education for collaboration: Learning how to improve health from interprofessional models across the continuum of education to practice: Workshop summary. Washington, DC: The National Academies Press; 2013.

36. Kent $\mathbf{F}$, Martin N, Keating $\mathbf{J L}$. Interprofessional student-led clinics: an innovative approach to the support of older people in the community. J Interprof Care. 2016;30(1):123-8.

37. Shunk R, Dulay M, Chou CL, Janson S, O'Brien BC. Huddle-coaching: a dynamic intervention for trainees and staff to support team-based care. Acad Med. 2014;89(2):244-50. 
38. Parsell G, Bligh J. The development of a questionnaire to assess the readiness of health care students for interprofessional learning (RIPLS). Med Educ. 1999;33:95-100.

39. Schwind CJ, Boehler ML, Markwell SJ, Williams RG, Brenner MJ. Use of simulated pages to prepare medical students for internship and improve patient safety. Acad Med. 2011;86(1):77-84.

40. Carrachio C, Englander R, Gilhooly J, et al. Building a framework of entrustable professional activities, supported by competencies and milestones to bridge the educational continuum. Acad Med. 2017;92(3):324-30.

41. Shaughnessy AF, Sparks J, Cohen-Osher M, Goodell KH, Sawin GL, Gravel J. Entrustable professional activities in family medicine. J Grad Med Educ. 2013;5:112-18.

42. Lomis K, Amiel JM, Ryan MS, Esposito K, Green M, Stagnaro-Green A, Bull J, Mejicano G, for the AAMC Core EPAs for Entering Residency
Pilot Team. Implementing an Entrustable Professional Activities Framework in Undergraduate Medical Education: Early Lessons From the AAMC Core Entrustable Professional Activities for Entering Residency Pilot. Acad Med. 2017;92(6):765-70. doi:10.1097/AMC. 0000000000001543.

43. Caverzagie KJ, Cooney TG, Hemmer PA, Berkowitz L. The development of entrustable professional activities for internal medicine residency training: a report from the education redesign committee of the Alliance for Academic Internal Medicine. Acad Med. 2015;90:479-84.

44. Carrachio C, Englander R, Holmbe E, Kogan JR. Driving care quality: aligning trainee assessment and supervision through practical application of entrustable professional activities, competencies and milestones. Acad Med. 2016:91(2):199-203. 